\title{
Optimal Frequencies for Inductive Powering of Fully Implantable Biosensors for Chronic and Elderly Patients
}

\author{
Jacopo Olivo, Sandro Carrara, and Giovanni De Micheli \\ Integrated Systems Laboratory \\ École Polytechnique Fédérale de Lausanne - EPFL \\ Lausanne, Switzerland \\ (sandro.carrara@epfl.ch)
}

\begin{abstract}
The paper aims at exploring advantages and drawbacks of using high-frequency inductive links to transmit power wirelessly to implanted biosensors. A system with an external transmitting coil located into a skin patch and a receiving coil embedded into a fully implanted biosensor is simulated. The effects of the geometry of the coils on the optimal working frequencies and on the power gain have been analyzed. For applications dedicated to elderly and chronic patients, attention has been posed to the effects on link efficiency of different implantation sites and possible misalignments between the coils.
\end{abstract}

\section{INTRODUCTION}

Remote and continuous monitoring of relevant human metabolites, such as glucose and lactate, is of crucial importance for chronic and elderly patients. It enables a constant monitoring of their status by returning a "telemetry" of their health condition. This scenario may be feasible by using subcutaneous biosensors, implanted into the interstitial regions of different parts of the body, depending on the different diseases. The size of such devices is a key feature to reduce their invasivity and to enable a long-time monitoring of chronic patients at home. The use of remote powering techniques can avoid the presence of embedded batteries, thus reducing the invasivity of the system and the discomfort of the patients.

Inductive links are widely used for remote powering of implantable biosensors [1-8] and typically operate at frequencies below $10 \mathrm{MHz}$. This upper limit is often proposed to minimize the quantity of power absorbed by the tissues and to increase the link efficiency. Recent works based on fullwave analysis $[9,10]$ have questioned this assumption by showing that the penetration depth of the electromagnetic fields into the human body is asymptotically independent of the frequency. Thus, ref. [11] has proposed an inductive link operating at $915 \mathrm{MHz}$, in the microwave range.

This work is part of the i-IronIC project within the NanoTera program.

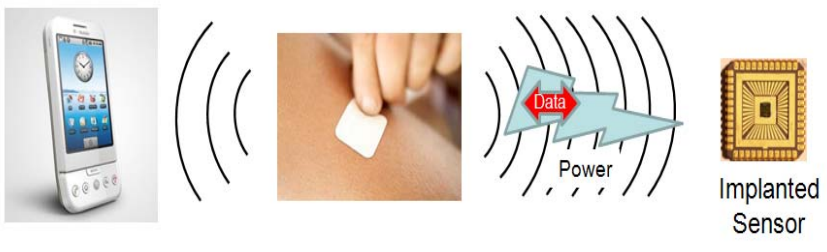

Figure 1. In the envisaged scenario the trasmitting coil, embedded into a patch, transmits power and data to the implanted biosensor. Data returned by the biosensor are read by the patch and sent to a remote station.

The use of high frequency links enables a drastic reduction in the size of the implanted coil; for example, the receiving coil realized in [11] is just $4 \mathrm{~mm}^{2}$. The reduction of the implanted coil is a key feature to reduce the pain of the patient.

The goal of this work is to explore the use of high frequency inductive links to power an implanted biosensor. The powering of that sensor is achieved by means of a patch attached to the skin, directly over the implantation zone, as shown in Fig. 1.

The paper is organized as follows. Section 2 introduces the model used to calculate the electrical properties of the body tissues. Section 3 shows the results returned by the simulations. Finally, Section 4 concludes the paper.

\section{EleCtricAl PROPERTIES OF THE Body TISSUES}

In order to study the efficiency of inductive powering through different body tissues, it is necessary to define their electrical properties over a wide range of frequencies. A large number of tissues have been modeled at different frequencies by means of the Cole-Cole dispersion model [12]. This model returns the complex permittivity of a tissue as a function of the angular frequency $\omega$ of the incident electromagnetic field:

$$
\hat{\varepsilon}(\omega)=\varepsilon_{\infty}+\sum_{n} \frac{\Delta \varepsilon_{n}}{1+\left(j \omega \tau_{n}\right)^{\left(1-\alpha_{n}\right)}}+\frac{\sigma_{\mathrm{i}}}{\mathrm{j} \omega \varepsilon_{0}},
$$


where $\tau$ is a time constant characterizing the polarization mechanism, $\alpha$ is a measure of the broadening of the dispersion, $\varepsilon_{0}$ is the permittivity of the vacuum, and $\sigma_{i}$ is the static ionic conductivity of the tissue. The term $\varepsilon_{\infty}$ is the permittivity of the tissue at field frequencies where $\omega \tau \gg 1$. Finally, $\Delta \varepsilon_{n}=\varepsilon_{s}-\varepsilon_{\infty}$, where $\varepsilon_{s}$ is the permittivity of the tissue at field frequencies where $\omega \tau \ll 1$. The value of the parameters just introduced is reported in [12] for a large variety of body tissues.

Different implantation sites have been investigated by means of the Visible Human Server [13] that enables 3D real time navigation inside the human body (Fig. 2). The different tissues have been modeled in the simulation tool Agilent Momentum [14], in order to perform full-wave analyses in different parts of the human body.

The following implantation zones have been considered in the simulations: arm, forearm, abdomen, and leg. The description of the tissues present in these different implantation areas is reported in Table I, including the location of the coils.

\section{SiMULATIONS AND DisCUSSION}

The effects on the link efficiency of different factors, such as geometry of the coils, misalignments due to erroneous patch placement, and implantation depth of the receiving coil are shown in this section. The efficiency, in terms of power transfer, is evaluated by the maximum power gain of the inductive link. The maximum power gain is defined as the transducer power gain $G_{T}$ of the link when the load and the source connected to the system have impedance matched with the output and input impedances of the link, respectively [15]. The transducer power gain $G_{T}$ can be calculated directly from the scattering parameters $S_{i j}$ of the link, obtained with the simulation tool Agilent Momentum [14]:

$$
\begin{aligned}
& \mathrm{G}_{T}= \frac{\text { Power delivered to the load }}{\text { Power available from the source }}= \\
&= \frac{1-\left|\Gamma_{\mathrm{S}}\right|^{2}}{\left|1-\Gamma_{\mathrm{in}} \Gamma_{\mathrm{S}}\right|^{2}} \cdot\left|\mathrm{S}_{21}\right|^{2} \cdot \frac{1-\left|\Gamma_{\mathrm{L}}\right|^{2}}{\left|1-\mathrm{S}_{22} \Gamma_{\mathrm{L}}\right|^{2}}, \\
& \text { TABLE I. IMPLANTATION SITES }
\end{aligned}
$$

\begin{tabular}{|c|c|c|c|}
\hline Arm & Forearm & Abdomen & Leg \\
\hline $\begin{array}{c}\frac{\text { External Coil }}{\text { Air }-1 \mathrm{~mm}} \\
\text { Skin }-1.5 \mathrm{~mm} \\
\text { Fat }-4.5 \mathrm{~mm} \\
\text { Air }-1 \mathrm{~mm} \\
\text { Receiving Coil } \\
\text { Air }-1 \mathrm{~mm} \\
\text { Fat }-4.5 \mathrm{~mm} \\
\text { Muscle }-36 \mathrm{~mm} \\
\text { Humerus } 18 \mathrm{~mm} \\
\text { Muscle }-48 \mathrm{~mm} \\
\text { Fat }-9 \mathrm{~mm} \\
\text { Skin }-1.5 \mathrm{~mm}\end{array}$ & $\begin{array}{c}\text { External Coil } \\
\text { Air }-1 \mathrm{~mm} \\
\text { Skin }-2 \mathrm{~mm} \\
\text { Fat }-1.5 \mathrm{~mm} \\
\text { Air }-1 \mathrm{~mm} \\
\text { Receiving } \\
\text { Coil } \\
\text { Air }-1 \mathrm{~mm} \\
\text { Fat }-1.5 \mathrm{~mm} \\
\text { Muscle }-12 \mathrm{~mm} \\
\text { Ulna }-5 \mathrm{~mm} \\
\text { Muscle }-2 \mathrm{~mm} \\
\text { Radius }-3 \mathrm{~mm} \\
\text { Muscle }-12 \mathrm{~mm} \\
\text { Blood }-5 \mathrm{~mm} \\
\text { Muscle }-4 \mathrm{~mm} \\
\text { Blood }-4 \mathrm{~mm} \\
\text { Muscle }-8 \mathrm{~mm} \\
\text { Fat }-3 \mathrm{~mm} \\
\text { Skin }-2 \mathrm{~mm}\end{array}$ & $\begin{array}{c}\frac{\text { External Coil }}{\text { Air }-1 \mathrm{~mm}} \\
\text { Skin }-2 \mathrm{~mm} \\
\text { Fat }-2 \mathrm{~mm} \\
\text { Air }-1 \mathrm{~mm} \\
\text { Receiving Coil } \\
\text { Air }-1 \mathrm{~mm} \\
\text { Fat }-2 \mathrm{~mm} \\
\text { Muscle }-17 \mathrm{~mm} \\
\text { Colon }-40 \mathrm{~mm} \\
\text { Fat }-40 \mathrm{~mm} \\
\text { Intestine-33mm } \\
\text { Blood }-17 \mathrm{~mm} \\
\text { Spine }-56 \mathrm{~mm} \\
\text { Muscle }-83 \mathrm{~mm} \\
\text { Fat }-10 \mathrm{~mm} \\
\text { Skin }-2 \mathrm{~mm}\end{array}$ & $\begin{array}{l}\frac{\text { External Coil }}{\text { Air }-1 \mathrm{~mm}} \\
\text { Skin }-2 \mathrm{~mm} \\
\text { Fat }-3 \mathrm{~mm} \\
\text { Air }-1 \mathrm{~mm} \\
\text { Receiving Coil } \\
\text { Air }-1 \mathrm{~mm} \\
\text { Fat }-3 \mathrm{~mm} \\
\text { Muscle }-45 \mathrm{~mm} \\
\text { Femur }-14 \mathrm{~mm} \\
\text { Muscle }-45 \mathrm{~mm} \\
\text { Fat }-6 \mathrm{~mm} \\
\text { Skin }-2 \mathrm{~mm}\end{array}$ \\
\hline
\end{tabular}

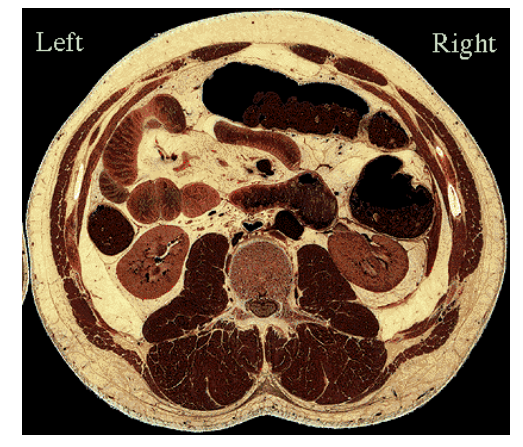

Figure 2. Slice of the human abdomen obtained with the Visible Human Server [13]. In the slice are visible: spinal cord, kidneys, colon, and small intestine.

where $\Gamma_{\text {in }} \doteq \mathrm{S}_{11}+\frac{\mathrm{S}_{12} \mathrm{~S}_{21} \Gamma_{\mathrm{L}}}{1-\mathrm{S}_{22} \Gamma_{\mathrm{L}}}$. The terms $\Gamma_{\mathrm{S}}$ and $\Gamma_{\mathrm{L}}$ are the reflection coefficients of the source and the load, respectively [15].

The geometry of the internal coil is chosen to be inserted together with the biosensor into a needle, like those of the syringes. Thus, the biosensor can be implanted containing the pain of the patient. The implanted coil is a single-turn, rectangular coil. The short side is set equal to $0.9 \mathrm{~mm}$; this value is compatible with the diameter of commercial needles. The coil has been simulated as a microstrip of copper with a thickness of $38.1 \mu \mathrm{m}$. The width of the copper track is $0.2032 \mathrm{~mm}$. The external coil has tracks with width of $2.032 \mathrm{~mm}$. Similarly to the internal coil, the external coil has been simulated as a microstrip of copper with a thickness of $38.1 \mu \mathrm{m}$.

\section{A. Effects of the geometry of the coils on the power gain}

This set of simulations is obtained with the receiving coil implanted into the arm. The results are shown in Fig. 3. A reduced size of the coils causes a higher optimal frequency, together with a reduced maximum power gain. For the tested geometries, the optimal frequency is located always over $100 \mathrm{MHz}$, at least one order of magnitude higher than the frequencies commonly used [1-8]. With the largest geometry the link efficiency is about $30 \%$.

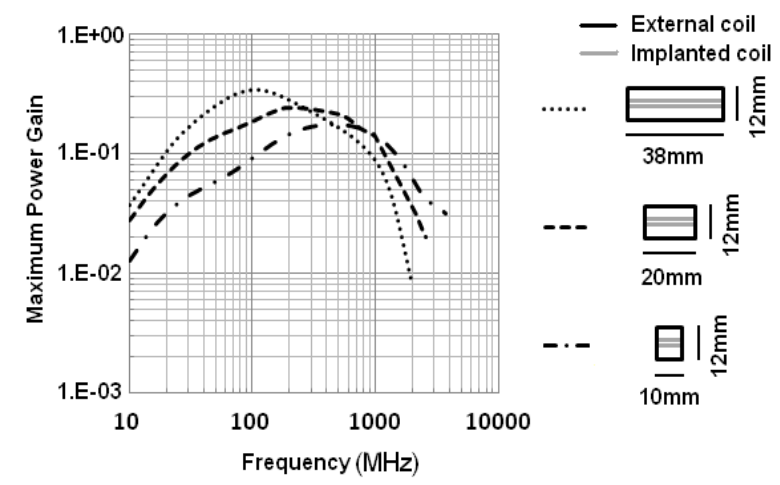

Figure 3. Maximum power gain for different geometries of the coils. A reduced size of the coils causes a higher optimal frequency, together with a reduced maximum power gain. 


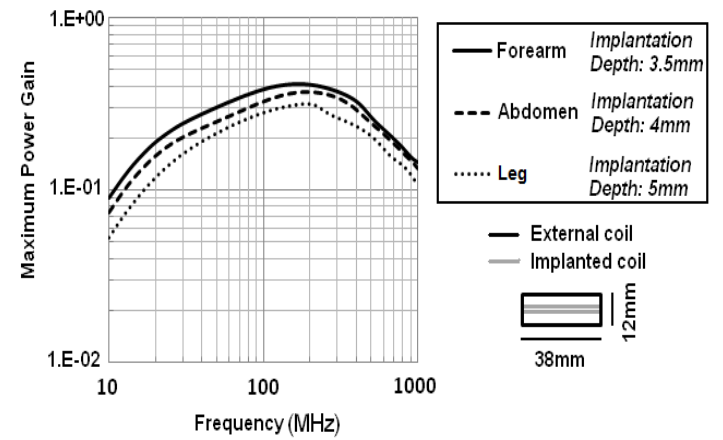

Figure 4. Different implantation areas are tested with the geometry of the coils constant. The different implantation depth influences the maximum power gain.

\section{B. Different Implantation Sites}

The implantation sites depend on several factors, such as the kind of substances to be detected or the tissues to be checked. For instance, the monitoring of glucose in elderly patients or diabetics can be performed in the interstitial regions of the abdomen, while the monitoring of lactate in sportsmen must be performed in the interstitial regions of the limbs under stress. Thus, different implantation zones have been tested, keeping fixed the geometries of the coils. The results obtained are shown in Fig. 4. The optimal frequency does not change by implanting the receiving coil in the different zones. Moreover, the maximum power gain depends on the implantation depth and decreases with deeper implanted coils. The differences of tissues in the different implantation zones do not affect the maximum power gain.

\section{Lateral Misalignment}

Misalignments between the coils can occur due to erroneous placement of the patch or difficulties in locating the exact implantation zone. Thus, lateral misalignments between the coils are simulated for a given geometry (Fig. 5). The simulations are realized with the receiving coil implanted into the arm. Lateral misalignments strongly affect the maximum power gain, while they do not shift the optimal frequency. Lateral misalignments over $20 \mathrm{~mm}$ seriously compromise the efficiency of the inductive link.

\section{Multiple-Turn External Coils}

Simulations have been performed using external coils with multiple turns. The results are shown in Fig. 6. For two simulations (14 turns and 29 turns), the width of the tracks of the external coil is fixed at $0.2032 \mathrm{~mm}$, while the spacing among the coil tracks is $0.2 \mathrm{~mm}$. In the third simulation (30 turns) the width of the tracks is $0.254 \mathrm{~mm}$, while the spacing among tracks is $0.14 \mathrm{~mm}$. The optimal frequency is always lower than in the case where a single-turn external coil is used. In the case of a 30 turns external coil the optimal frequency is about $10 \mathrm{MHz}$, at least one order of magnitude lower than the optimal frequencies obtained from the previous simulations.

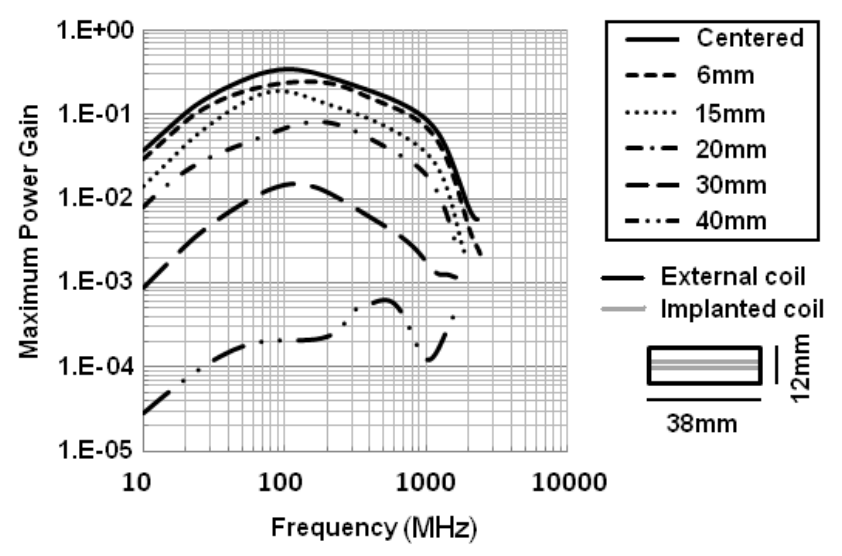

Figure 5. Different lateral misalignments between the coils have been simulated for a given geometry. The misalignments do not affect the optimal frequency.

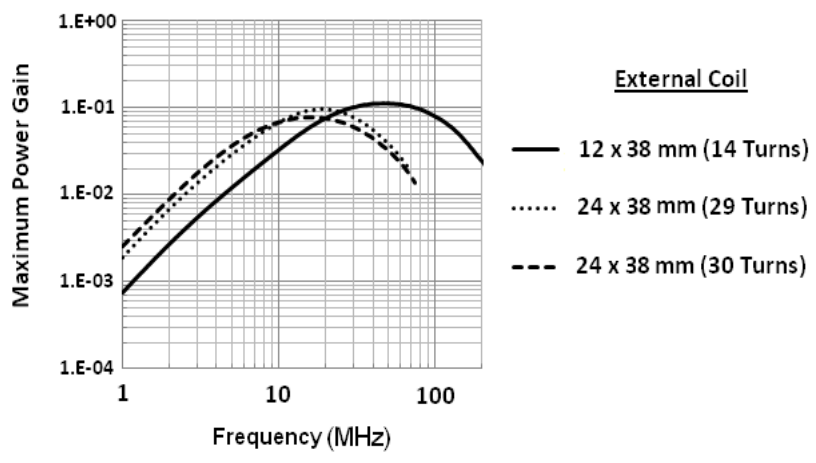

Figure 6. Maximum power gain obtained with multiple-turns external coils. The number of turns and the geometry of the external coils affect the optimal frequency.

\section{E. Discussion}

The effects of different factors such as geometry of the coils, misalignments due to erroneous placements of the patch, and implantation depths on the inductive powering have been investigated with full-wave simulations. Using single-turn rectangular coils, the optimal working frequencies are at least one order of magnitude higher than the frequencies commonly used for inductive remote powering. Fig. 7 resumes the behaviors of the optimal frequency and of the maximum power gain as a function of different factors, such as length of the coils, lateral misalignments, and implantation depths.

The optimal working frequency is highly influenced by the size of the coils, while it is not affected by the implantation depth and by lateral misalignments. With smaller coils the optimal frequency increases while the maximum power gain decreases. Lateral misalignments and implantation depth strongly influence the maximum power gain, while they do not excessively affect the optimal working frequency. Finally, the use of a larger external coil with multiple turns shifts the optimal frequency one order of magnitude lower, close to the range of commonly used frequencies. 


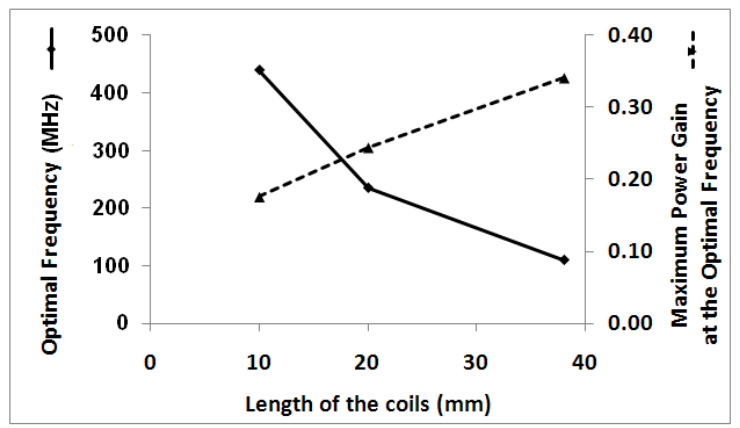

(a)

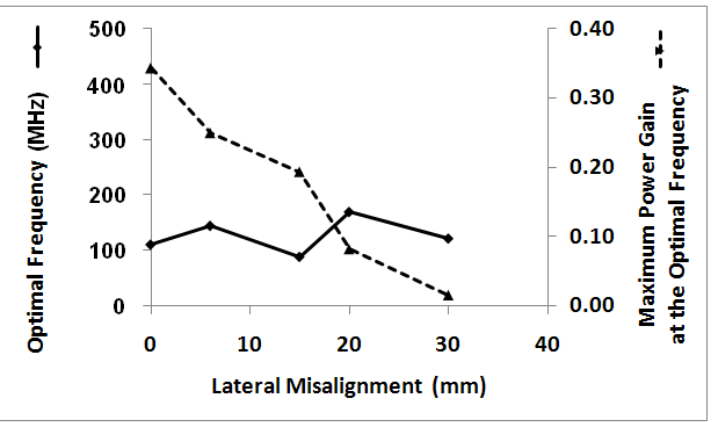

(b)

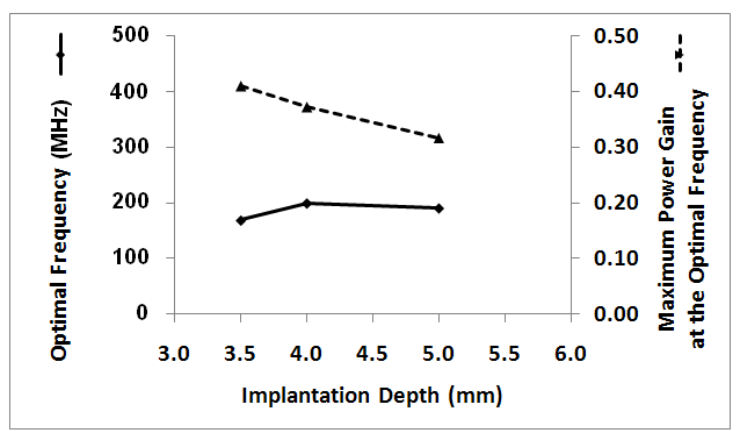

(c)

Figure 7. The behaviors of the optimal frequency and of the maximum power gain versus different factors, such as (a) length of the coils, (b) lateral misalignments, and (c) implantation depths are shown.

\section{CONCLUSIONS}

Remote and continuous monitoring of relevant human metabolites can be performed by means of biosensors implanted in the interstitial regions of different parts of the body. The powering of such devices can be realized wirelessly through the tissues by means of inductive links. The effects of the geometry of the coils on the optimal frequency have been investigated. Moreover, the effects of lateral displacements between the coils and different implantation sites have been taken into account.

When a pair of single turn coils is used, the optimal frequencies are at least one order of magnitude higher than the ones commonly used in inductive powering. Furthermore, implantation depth and lateral misalignments do not affect the optimal frequency, while they influence the maximum power gain.

\section{ACKNOWLEDGMENTS}

J.O. thanks J. Anders from EPFL and A. A.M. Perez from Agilent Technologies for the precious suggestions and the useful discussions on microwave networks and scattering parameters; K. M. Silay and Dr. C. Dehollain from EPFL for the advice on inductive links and their practical realization.

\section{REFERENCES}

[1] T. Akin, K. Najafi, and R. Bradley, "A Wireless Implantable Multichannel Digital Neural Recording System for a Micromachined Sieve Electrode," IEEE Journal of Solid-State Circuits, vol. 33, no. 1, pp. 109-118, Jan. 1998.

[2] C. Sauer, M. Stanacevic, G. Cauwenberghs, N. Thakor, "Power Harvesting and Telemetry in CMOS for Implanted Devices," IEEE Transactions on Circuits and Systems I: Regular Paper, vol. 52, no. 12, pp. 2605-2613, Dec. 2005

[3] B. Lenaerts and R. Puers, "An Inductive Power Link for a Wireless Endoscope," Biosensors and Bioelectronics, vol. 22, no. 7 , pp. 13901395, 2007.

[4] K. Silay, D. Dondi, L. Larcher, M. Declercq, L.Benini, Y. Leblebici, and C. Dehollain, "Load Optimization of an Inductive Power Link for Remote Powering of Biomedical Implants," Proceedings of the IEEE International Symposium on Circuits and Systems 2009 (ISCAS'09), pp. 533-536, May 2009.

[5] M. Catrysse, B. Hermans, and R. Puers, "An Inductive Power System with Integrated Bi-directional Data-transmission," Sensors and Actuators A: Physical, vol. 115, no. 2-3, pp.221-229, Sep.2004.

[6] J. Parramon, P. Doguet, D. Marin, M. Verleyssen, R. Munoz, L. Leija, and E. Valderrama, "Asic-based Batteryless Implantable Telemetry Microsystem for Recording Purposes," Proceedings of the $19^{\text {th }}$ Annual International Conference of the IEEE Engineering in Medicine and Biology Society, vol. 5, 1997, pp.2225-2228.

[7] G.Gudnason, E. Bruun, and M. Haugland, "A chip for an Implantable Neural Stimulator," Analog Integrated Circuits and Signal Processing, vol. 22, no. 1, pp. 81-89, 2000

[8] B. Smith, Z. Tang, M. Johnson, S. Pourmehdi, M. Gazdik, J. Buckett, and P. Peckham, "An externally powered, multichannel, implantable stimulator-telemeter for control of Paralyzed Muscle," IEEE Transactions on Biomedical Engineering, vol. 45, no. 4, pp. 463-475, Apr 1998. 
[9] A. Poon, S. O'Driscoll, and T.Meng, "Optimal Operating Frequency in Wireless Power Transmission for Implantable Devices," Proceedings of the $29^{\text {th }}$ Annual International Conference of the IEEE EMBS, pp.56735678, 2007.

[10] A. Poon, S. O'Driscoll, and T.Meng, "Optimal Frequency for Wireless Power Transmission into Dispersive Tissue," IEEE Transactions on Antennas and Propagation, vol. 58, no. 5, pp. 1739-1750, 2010.

[11] A. Poon, S. O’Driscoll, and T.Meng, "A mm-sized Implantable Power Receiver with Adaptative Link Compensation," Technical Digest of IEEE International Solid-State Circuits Conference, Paper 17.5, 2009.
[12] S. Gabriel, R. Laum and C. Gabriel, "The Dielectric Properties of Biological Tissues: III. Parametric Models for the Dielectric Spectrum of Tissues," Physics in Medicine and Biology, vol. 41, pp.2271-2293, 1996.

[13] Visible Human Server, http//visiblehuman.epfl.ch/index.php

[14] Agilent Momentum, http://cp.literature.agilent.com/litweb/pdf/59899597EN.pdf

[15] D. Pozar, Microwave Engineering -Third Edition. John Wiley \& Sons, 2005. 